\title{
The Evaluation of Benefit of Newly Prepared Reversible Inhibitors of Acetylcholinesterase and Commonly Used Pyridostigmine as Pharmacological Pretreatment of Soman-Poisoned Mice
}

\author{
Jiří Kassa*, Jan Korábečný, Eugenie Nepovimová
}

\section{ABSTRACT}

Aim: The ability of four newly prepared reversible inhibitors of acetylcholinesterase (6-chlorotacrine, 7-phenoxytacrine, compounds 1 and 2) and currently used carbamate pyridostigmine to increase the resistance of mice against soman and the efficacy of antidotal treatment of soman-poisoned mice was evaluated. Methods: The evaluation of the effect of pharmacological pretreatment is based on the identification of changes of soman-induced toxicity that was evaluated by the assessment of its $L_{50}$ value and its $95 \%$ confidence limit using probitlogarithmical analysis of death occurring within $24 \mathrm{~h}$ after administration of soman. Results: 6 -chlorotacrine was only able to markedly protect mice against acute toxicity of soman. In addition, the pharmacological pretreatment with 6-chlorotacrine or compound 2 was able to increase the efficacy of antidotal treatment (the oxime $\mathrm{HI}-6$ in combination with atropine) of soman-poisoned mice. The other newly prepared reversible inhibitors of acetylcholinesterase (7-phenoxytacrine, compound 1) as well as commonly used pyridostigmine did not influence the efficacy of antidotal treatment. Conclusion: These findings demonstrate that pharmacological pretreatment of somanpoisoned mice can be promising and useful in the case of administration of 6-chlorotacrine and partly compound 2.

\section{KEYWORDS}

soman; reversible inhibitors of acetylcholinesterase; antidotes; pharmacological pretreatment; mice

\section{AUTHOR AFFILIATIONS}

Department of Toxicology and Military Pharmacy, University of Defence, Faculty of Military Health Sciences, Hradec Králové, Czech Republic

* Corresponding author: Třebešská 1575, Faculty of Military Health Sciences, 50001 Hradec Králové, Czech Republic; e-mail: kassa@pmfhk.cz 


\section{INTRODUCTION}

The highly toxic organophosphorus compounds, called nerve agents, are still considered to be the most dangerous chemical warfare agents. They pose potential threats to both military and civilian populations, as evidenced in terroristic attacks in Japan (1). Organophosphorus nerve agents exert their toxic effects mainly by inhibiting acetylcholinesterase (AChE, EC 3.1.1.7) and subsequent accumulation of acetylcholine (ACh) in the central and peripheral nervous systems and stimulation of both muscarinic and nicotinic cholinergic receptors. Death occurs due to an acute cholinergic crisis, with signs and symptoms such as excessive salivation, lacrimation, urination, defecation, sweating, bronchoconstriction, neuromuscular block, generalized seizures, respiratory distress and respiratory failure (2-3).

The current standard treatment for poisoning by nerve agents consists of the combined administration of anticholinergic drugs such as atropine sulfate and AChE reactivators such as pralidoxime, obidoxime or HI-6. Generally, anticholinergics (mainly atropine) are used for relieving muscarinic signs and symptoms whereas AChE reactivators (generally nucleophilic compounds with high affinity for phosphorus), also called oximes, are used to repair the biochemical lesion by dephosphonylation of AChE and restoring its activity. Although the antidotes against nerve agents and organophosphorus insecticides have been developed based on the knowledge of above-mentioned basic mechanism of acute toxicity, their efficacy is limited (4-5).

One of the most resistant nerve agents is soman (pinacolyl methylfluorophosphonate). Its deleterious effects are extraordinarily difficult to counteract due to the very rapid aging of soman-inhibited $\mathrm{AChE}(2,6)$. In addition, the main action of soman is in the central nervous system where the reactivating efficacy of all oximes is low owing to their limited penetration through blood-brain barrier (7-8). The unsatisfactory antidotal treatment available for acute nerve agent poisonings, especially in the case of soman, cyclosarin and tabun exposure, has brought another approach how to protect the humans from nerve agent-induced acute lethal toxic effects - using "pharmacological pretreatment" in the case the threat of exposure to nerve agents occurs. This approach generally represents the medical countermeasures applied relatively shortly before the penetration of a toxic agent into the organism with the aim of protecting the organism against the toxic drug and increasing the effects of post-exposure antidotal treatment. It appears from toxicodynamic point of view that prophylactic countermeasures can bring two main actions: protection of $\mathrm{AChE}$ against irreversible inhibition and antagonisation of the action of accumulated ACh. Thus, the pharmacological pretreatment allows survival and increase the resistance of organisms exposed to nerve agents as previously described (9-11).

Up to date, the most common principle of pharmacological pretreatment is the protection of AChE against nerve agent-induced irreversible inhibition that is focused on the use of reversible cholinesterase inhibitors. Among reversible inhibitors of $\mathrm{AChE}$, the carbamate pyridostig- mine bromide is generally accepted and commonly used for the pharmacological pretreatment of nerve agent poisonings. However, pyridostigmine is only able to protect peripheral AChE from irreversible nerve agent-induced AChE phosphonylation, while nerve agents, especially fluorophosphonates, can cross the blood-brain barrier (BBB) and, thus, express their deleterious effects through their central toxic effects including centrally mediated seizure activity that can rapidly progress to status epilepticus and finally contribute to brain damage (2).

Thus, the replacement of pyridostigmine bromide with sufficiently effective reversible inhibitors of AChE with low toxicity and ability to cross the blood-brain barrier has been an important goal for the pharmacological pretreatment of nerve agent poisonings because the small decrease of the brain AChE activity (up to $20 \%$ ) was found to be beneficial for an increase in the efficacy of pharmacological pretreatment and does not affect the behavioral and neurophysiological functions of experimental animals according to our neurobehavioral research (12). Recently, four novel reversible inhibitors of AChE - 6-chlorotacrine (6-chloro-1,2,3,4-tetrahydroacridine-9-amine hydrochloride), 7-phenoxytacrine (7-phenoxy-1,2,3,4-tetrahydroacridine-9-amine hydrochloride), compound 1 (6-hydrazil-N-\{6-[(7-methoxy-1,2,3,4-tetrahydroacridine-9-yl) amino]hexyl\} pyridine-3-carboxamide hydrochloride) and compound 2 (6-hydrazil-N-\{6-[(1,2,3,4-tetrahydroacridine-9-yl)amino] hexyl\} pyridine-3-carboxamide hydrochloride) (Figure 1) were synthesized at our Department of Toxicology and Military Pharmacy to improve the efficacy of pharmacological pretreatment against nerve agents and potentially for the treatment of Alzheimer's disease. All newly prepared reversible inhibitors od AChE are tacrine-related compounds. Tacrine itself failed as a prophylactic agent because of small difference between pharmacologically effective and toxic doses. Therefore, we were searching for tacrine-related compounds with bigger differences between therapeutic and toxic doses.

In the present study, the influence of pyridostigmine and four newly prepared reversible inhibitors of AChE (6-chlorotacrine, 7-phenoxytacrine, compounds 1 and 2) on the resistance of soman-exposed mice and on the therapeutic efficacy of currently used antidotal treatment (the oxime HI- 6 in combination with atropine) of soman-induced acute poisoning was compared.

\section{MATERIALS AND METHODS}

\section{ANIMALS}

Male NMRI mice weighing 18-22 g were purchased from VELAZ (Prague, Czech Republic). They were kept in an air-conditioned room $\left(22 \pm 2{ }^{\circ} \mathrm{C}\right.$ and $50 \pm 10 \%$ relative humidity, with lights from $7.00 \mathrm{hrs}$ a.m. to $7.00 \mathrm{hrs} \mathrm{p.m.)}$ and allowed access to standard food and tap water ad libitum. The rats were divided into groups of eight animals $(\mathrm{N}=8)$. Handling of experimental animals was done under the supervision of the Ethics Committee of the Faculty of Military Health Sciences in Hradec Králové (Czech Republic). 


\section{CHEMICALS}

Soman was obtained from the Military Technical Institute in Brno (Czech Republic) and was $95.0 \%$ pure. Its purity was assayed by acidimetric titration. The purity of all reversible inhibitors of AChE (Figure 1) was higher than $98 \%$. They were synthesized earlier at the Department of Toxicology and Military Pharmacy of the Faculty of Military Health Sciences in Hradec Kralove (Czech Republic) with the exception of pyridostigmine bromide that was purchased from LITOLAB (Chudobin, Czech Republic). The purity of newly synthesized reversible inhibitors of AChE was analysed using HPLC. All other drugs and chemicals of analytical grade were obtained commercially and used without further purification. All substances were administered intramuscularly (i.m.) at a volume of $10 \mathrm{~mL} / \mathrm{kg}$ body weight (b.w.).<smiles>CN(C)C(=O)Oc1ccc[n+](C)c1</smiles>

pyridostigmine bromide<smiles>Nc1c2c(nc3cc(Cl)ccc13)CCCC2</smiles>

6-chlorotacrine<smiles>Nc1c2c(nc3ccc(Oc4ccccc4)cc13)CCCC2</smiles>

7-phenoxytacrine<smiles>COc1ccc2nc3c(c(NCCCCCCNC(=O)c4ccc(NN)nc4)c2c1)CCCC3</smiles>

FIG. 1: Chemical structure of reversible inhibitors of AChE studied.

\section{EVALUATION OF ACUTE TOXICITY OF REVERSIBLE INHIBITORS OF ACHE}

Before starting the evaluation of prophylactic efficacy of AChE reversible inhibitors, the acute toxicity of all tested inhibitors was evaluated in mice by the assessment of their $\mathrm{LD}_{50}$ values and their $95 \%$ confidence limits (CL) using probit-logarithmical analysis of death occurring within 24 hours after i.m. administration of each inhibitor at five different doses with eight animals per dose (13).

\section{EVALUATION OF PROPHYLACTIC EFFICACY OF REVERSIBLE INHIBITORS OF ACHE}

To evaluate prophylactic efficacy of tested reversible inhibitors of AChE, the inhibitors (pyridostigmine, 6-chlorotacrine, 7-phenoxytacrine, compounds 1 and 2) were administered i.m. at doses corresponding to $5 \%$ of their $\mathrm{LD}_{50}$ values 30 minutes before i.m. soman challenge. The doses of tested reversible inhibitors of AChE were chosen to be sufficiently safe to avoid the potential adverse drug reactions in the peripheral as well as central compartment. Soman-induced toxicity was evaluated by the assessment of its $\mathrm{LD}_{50}$ value and its $95 \%$ confidence limit using probit-logarithmical analysis of death occurring within $24 \mathrm{~h}$ after administration of soman at five different doses with eight animals per dose (13). The efficacy of tested prophylactic drugs was expressed as protective ratio $\left(\mathrm{LD}_{50}\right.$ val- ue of soman in pretreated mice / $\mathrm{LD}_{50}$ value of soman in non-pretreated mice).

\section{EVALUATION OF THE INFLUENCE OF REVERSIBLE INHIBITORS OF ACHE ON THE THERAPEUTIC EFFICACY OF ANTIDOTAL TREATMENT}

To evaluate the influence of reversible inhibitors of AChE on the therapeutic efficacy of antidotal treatment, all tested AChE reversible inhibitors were administered 30 minutes before soman poisoning while antidotal treatment (the oxime $\mathrm{HI}-6$ at a dose corresponding to $5 \%$ of its $\mathrm{LD}_{50}$ in combination with atropine $-10 \mathrm{mg} / \mathrm{kg}$ ) was carried out by i.m. injection $1 \mathrm{~min}$ after soman administration. Soman-induced toxicity was evaluated by the assessment of $\mathrm{LD}_{50}$ value and its $95 \%$ confidence limit using probit-logarithmical analysis of death occurring within $24 \mathrm{~h}$ after administration of soman at five different doses with eight animals per dose (13). The influence of tested prophylactic drugs on the antidotal treatment of soman poisoning was expressed as protective ratio $A\left(L D_{50}\right.$ value of soman in pretreated mice with antidotal treatment / $\mathrm{LD}_{50}$ value of soman in non-pretreated mice without antidotal treatment) and protective ratio $\mathrm{B}\left(\mathrm{LD}_{50}\right.$ value of soman in pretreated mice with antidotal treatment $/ \mathrm{LD}_{50}$ value of soman in non-pretreated mice with antidotal treatment). The differences between $\mathrm{LD}_{50}$ values were considered to be significant when $\mathrm{p}<0.05(13)$. 


\section{RESULTS}

The acute i.m. toxicity of all reversible inhibitors of AChE in mice is summarized in Table 1 . The results show that the acute toxicity of newly prepared reversible inhibitors of AChE is quite different. While the acute toxicity of 7-phenoxytacrine, compound 2 and, especially, compound 1 is relatively low, the acute toxicity of 6-chlorotacrine is markedly higher although it is still lower than the acute toxicity of commonly used pyridostigmine. According to our results, the compound 1 seems to be the least toxic reversible inhibitor of $\mathrm{AChE}$ among all compounds studied.

A comparison of the prophylactic efficacy of pyridostigmine and all newly prepared reversible AChE inhibitors is presented in Table 2. Among all reversible inhibitors of AChE studied, 6-chlorotacrine was only able to markedly increase the resistance of experimental animals against acute toxicity of soman. Due to the prophylactic administration of 6-chlorotacrine, the $\mathrm{LD}_{50}$ value of soman was increased from $49.5 \mu \mathrm{g} / \mathrm{kg}$ to $67.3 \mu \mathrm{g} / \mathrm{kg}$. On the other hand, other reversible inhibitors of AChE including commonly used pyridostigmine were not able to influence the $\mathrm{LD}_{50}$ value of soman.

A comparison of the benefit of pyridostigmine and all newly prepared reversible AChE inhibitors for the therapeutic efficacy of antidotal treatment of soman poisoning is presented in Table 3 . Two newly prepared reversible inhibitors of AChE (6-chlorotacrine, compound 2) markedly increased the efficacy of the antidotal treatment of soman-poisoned mice consisting of the oxime HI- 6 and at- ropine. Due to the prophylactic administration of 6-chlorotacrine or compound 2 , the protective ratio induced by antidotal treatment of soman poisoning was increased from 2.39 to 3.25 , resp. 3.27. On the other hand, the prophylactic administration of other newly prepared reversible AChE inhibitors (7-phenoxytacrine, compound 1) as well as currently used pyridostigmine bromide did not influence the therapeutic efficacy of chosen antidotal treatment of soman-poisoned mice.

\begin{tabular}{|l|l|}
\hline Reversible inhibitor of AChE & $\mathbf{L D}_{50}(\mathrm{mg} / \mathrm{kg}) \pm 95 \% \mathrm{CL}$ \\
\hline Pyridostigmine bromide & $3.24(2.56-4.37)$ \\
\hline 6-chlorotacrine & $10.08(8.28-12.24)$ \\
\hline 7-phenoxytacrine & $86.0(61.0-109.1)$ \\
\hline 1 & $402.81(314.7-513.0)$ \\
\hline 2 & $57.28(46.5-78.0)$ \\
\hline
\end{tabular}

TAB. 1: Acute toxicity of reversible inhibitors of AChE in mice.

\begin{tabular}{|l|l|l|}
\hline Pretreatment & $\mathbf{L D}_{\mathbf{5 0}}(\mathbf{m g} / \mathbf{k g}) \pm \mathbf{9 5 \%} \mathbf{C L}$ & Protective ratio \\
\hline- & $49.5(34.0-72.1)$ & - \\
\hline $\begin{array}{l}\text { Pyridostigmine } \\
\text { bromide }\end{array}$ & $47.0(39.3-78.1)$ & 0.95 \\
\hline 6-chlorotacrine & $67.3(58.5-75.7)$ & 1.36 \\
\hline 7-phenoxytacrine & $50.2(38.5-65.7)$ & 1.01 \\
\hline 1 & $48.2(35.1-63.1)$ & 0.97 \\
\hline 2 & $50.1(34.6-54.0)$ & 1.01 \\
\hline
\end{tabular}

TAB. 2: Prophylactic effect of reversible inhibitors of AChE on the $\mathrm{LD}_{50}$ value of soman in mice.

\begin{tabular}{|c|c|c|c|c|}
\hline Pretreatment & Treatment & $\mathrm{LD}_{50}(\mathrm{mg} / \mathrm{kg}) \pm 95 \% \mathrm{CL}$ & Protective ratio $\mathrm{A}$ & Protective ratio $\mathrm{B}$ \\
\hline- & - & $92.3(73.7-143.6)$ & - & - \\
\hline- & $\begin{array}{l}\text { HI-6 } \\
\text { atropine }\end{array}$ & $220.5(189.8-297.3)^{*}$ & 2.39 & - \\
\hline Pyridostigmine bromide & $\begin{array}{l}\text { HI-6 } \\
\text { atropine }\end{array}$ & $238.1(202.4-309.4)^{*}$ & 2.58 & 1.08 \\
\hline 6-chlorotacrine & $\begin{array}{l}\mathrm{HI}-6 \\
\text { atropine }\end{array}$ & $299.9(240.8-408.2)^{*}$ & 3.25 & 1.36 \\
\hline 7-phenoxytacrine & $\begin{array}{l}\text { HI-6 } \\
\text { atropine }\end{array}$ & $196.7(150.9-239.5)^{*}$ & 2.13 & 0.89 \\
\hline 1 & $\begin{array}{l}\mathrm{HI}-6 \\
\text { atropine }\end{array}$ & $201.4(182.6-221.7)^{*}$ & 2.18 & 0.91 \\
\hline 2 & $\begin{array}{l}\text { HI-6 } \\
\text { atropine }\end{array}$ & $302.0(235.6-386.9)^{*}$ & 3.27 & 1.37 \\
\hline
\end{tabular}

TAB. 3: The influence of pharmacological pretreatment on the effect of antidotal treatment on the $\mathrm{LD}_{50}$ value of soman in mice. Statistical significance: ${ }^{*} p<0.05$ (between non-pretreated and non-treated mice and pretreated and/or treated mice).

\section{DISCUSSION}

Sufficiently effective pretreatment is considered to be very important especially in the case of soman exposure because soman-induced deleterious effects are extraordinarily difficult to counteract due to very low reactivating efficacy of currently used oximes (14). The reason for the weak reactivating potency of the oximes is very rapid aging of phosphonylated AChE (15-16).

Better therapeutic effects of antidotal treatment can be achieved by pretreatment with reversible AChE inhib- itors $(9,17)$. The protection of AChE against inhibition focused on the use of reversible AChE inhibitor is the most common principle of pharmacological pretreatment of nerve agent poisoning. Protection of AChE against inhibition - i.e. remaining intact $\mathrm{AChE}$ is a basic requirement for normal function of peripheral and central cholinergic nervous systems. Due to this pretreatment, the enzyme AChE became resistant to nerve agent-induced irreversible inhibition (18). It can be achieved by using reversible inhibitors (preferably carbamates) which are able to inhibit AChE reversibly with spontaneous recovery of the 
activity (decarbamylation). Recovered activity of AChE serves as a source of the active enzyme (9). The reversible cholinesterase inhibitor pyridostigmine bromide, a wellknown cholinesterase inhibitor, can be used for the treatment of Myasthenia gravis or for the prophylaxis against intoxication caused by organophosphorous nerve agents, especially against soman poisoning (19-21). Pyridostigmine is rapidly absorbed following oral administration determined as inhibition of the blood cholinesterases. The maximum inhibition is achieved 2-3 hours and lasts more than 8 hours. The half-life of inhibition is about 20 hours $(18-19,22)$. Based on these results, pyridostigmine was introduced into some armies as a prophylactic drug against nerve agents. Pyridostigmine bromide is stockpiled by various armed forces for pretreatment purpose against nerve agent poisoning and has been used by several thousand servicemen during UN operation against Iraq in 1991 (23). The important benefit of pyridostigmine bromide is the fact that it does not affect the combat readiness of the soldiers prior to nerve agent exposure and, therefore, it was chosen for the pretreatment of soldiers in the case of the threat of exposure to nerve agents. Nevertheless, our results demonstrate the shortage of effectiveness of pyridostigmine bromide alone to increase the resistance of nerve agent-exposed experimental animals (24). Its prophylactic effect is increased with its dose, however, higher doses cause more pronounced side effects. As pyridostigmine bromide is relatively toxic and the difference between its therapeutic and toxic dose is small, the safe dose for pharmacological pretreatment of nerve agent poisonings is limited and its prophylactic efficacy, when administered at safe doses, is unsatisfactory (25-26). In addition, it was demonstrated that exposure to physiologically relevant doses of pyridostigmine leads to neurobehavioral deficits and region-specific alterations in AChE and ACh receptors (27). It is known that commonly used pyridostigmine bromide as a prophylactic drug in the case of threat of exposure to nerve agents is able to protect just peripheral AChE. On the other hand, nerve agents, especially fluorophosphonates such as soman, sarin and cyclosarin, easily penetrate through BBB and markedly inhibit brain AChE. In addition, the currently used reactivators of nerve agent-inhibited $\mathrm{AChE}$, monopyridinium or bispyridinium oximes poorly penetrate through $\mathrm{BBB}$ and, therefore, their ability to reactivate nerve agent-inhibited $\mathrm{AChE}$ in the brain is very limited. The usage of reversible inhibitors of AChE, that are able to cross the BBB, brings the protection of brain AChE from ireversible inhibition by nerve agents. This fact is important and useful for the increase of resistance of organism against nerve agents and the increase of the efficacy of post-exposure antidotal treatment. Of course, it is necessary to be careful with the dosage of centrally acting prophylactic drug. The doses of reversible inhibitors of AChE must be sufficiently safe to avoid peripheral as well as central adverse drug reactions and to maintain battle readiness of troops. Therefore, the searching for less toxic, more effective and centrally active reversible inhibitors of AChE seems to be rationale to increase the effectiveness of pharmacological pretreatment of nerve agent poisonings. During recent years, numerous alternative substances with known anti-cholinesterase activity have been studied to evaluate their prophylactic efficacy in comparison with pyridostigmine bromide (2831 ). Some of them are already in clinical use or have been developed as potential therapeutics for other indications such as Myasthenia gravis (32) or Alzheimer's disease (AD) (33-34).

One of the promising approaches how to find sufficiently effective reversible inhibitor of AChE for the pharmacological pretreatment of nerve agent poisonings is to develop substituted analogues of tacrine. Tacrine (9-amino-1,2,3,4-tetrahydroacridine) is a reversible inhibitor of AChE that was launched in 1993 as the first drug for the symptomatic treatment of $\mathrm{AD}$ (35). However, recent evaluations of the clinical effects of tacrine have confirmed the adverse events consisting in the elevated liver transaminase levels and in dose-related peripheral cholinergic effects (36). Therefore, its clinical use as a drug for the treatment of AD was discontinued. Substituents in position 6 of the tetrahydroacridine moiety exerted relative steric freedom and favorable electron-attracting effect that represents a possibility of a hydrophobic interaction between some amino acid residues and substituents in position 6 of tacrine in the active site of AChE. On the other hand, substituents in position 7 of the tetrahydroacridine moiety exerted detrimental steric effect that represents strongly negative contribution for their enzyme inhibitory activity (37). This conclusion corresponds to our results. While tacrine derivative substituted in the position 6 (6-chlorotacrine) due to its increased inhibitory potency towards AChE was able to increase the resistance of experimental animals against lethal toxicity of soman and to increase the therapeutic efficacy of recommended antidotal treatment of acute soman poisoning, the tacrine derivative with a substitution in the position 7 (7-phenoxytacrine) was not effective. Novel multi-target directed ligands (tacrine-pyridine-3-carboxamide hybrids) 1 and 2 were selected upon their IC I0 $_{50}$ values $\left(1: h A C h E\right.$ IC $_{50}=3.81 \pm 2.4 \mu \mathrm{M}$; 2: $\left.h \mathrm{AChE} \mathrm{IC}_{50}=0.097 \pm 0.009 \mu \mathrm{M}\right)$ to confront the multifactorial nature of $\mathrm{AD}$ by combining $h \mathrm{ACh} E$ inhibitor with antioxidant action provided by hydrazinonicotinamide (38-39). Based on the inhibitory properties, compound 2 was able to increase the therapeutic efficacy of antidotal treatment of acute soman poisoning, while analogue of 7-methoxytacrine (compound 1) is not effective because the potency of 7-methoxytacrine to inhibit AChE is generally much lower compared to tacrine (7-methoxytacrine: $h \mathrm{AChE} \mathrm{IC}_{50}=10.00 \pm 1.0 \mu \mathrm{M}$; tacrine: $\mathrm{hAChE} \mathrm{IC}_{50}=0.32 \pm$ $0.01 \mu \mathrm{M})(40)$. Generally, the tacrine analogues exerting the sufficient prophylactic efficacy due to their potency to reversibly inhibit AChE in the peripheral and central nervous systems are more toxic. However, the acute toxicity of effective tacrine analogues studied is significantly lower compared to commonly used pyridostigmine and, therefore, their safe dose is higher and more effective.

\section{CONCLUSION}

In spite of some promising results in the case of prophylactic administration of 6-chlorotacrine and compound 2 , the basic principle of pharmacological preatreatment of 
nerve agent poisonigs - the protection of AChE from nerve agent-induced irreversible inhibition by administration of reversible AChE inhibitors is somewhat limited, especially by relatively high toxicity of sufficiently effective reversible inhibitors of AChE. On the other hand, our results also show that it is possible to develop sufficiently effective, centrally acting reversible inhibitors of AChE that are more effective and less toxic drugs for pharmacological pretreatment of nerve agent exposure than commonly used pyridostigmine bromide.

\section{ACKNOWLEDGEMENTS}

The authors express their appreciation to Mrs J. Uhlíŕová for her skill technical assistance. The study was funded by the grant of Ministry of Defense of the Czech Republic - "Long-term organization development plan Medical Aspects of Weapons of Mass Destruction of the Faculty of Military Health Sciences, University of Defence".

\section{REFERENCES}

1. Yanagisawa N, Morita H, Nakajima T. Sarin experience in Japan. Acute toxicity and long-term effects. J Neurol Sci 2006; 249: 76-85.

2. Bajgar J. Organophosphate/nerve agent poisoning: mechanism of action, diagnosis, prophylaxis and treatment. Adv Clin Chem 2004; 38: 151-216.

3. Colovic MB, Krstic DZ, Lazarevic-Pasti TD, Bondzic AM, Vasic VM. Acetylcholinesterase Inhibitors: Pharmacology and Toxicology. Curr Neuropharmacol 2013; 11:315-35.

4. Jokanovic M, Prostran, M. Pyridinium oximes as cholinesterase reactivators. Structure-activity relationship and efficacy in the treatment of poisoning with organophosphorus compounds. Curr Med Chem 2009; 16: 2177-88.

5. Kassa, J. Review of oximes in the antidotal treatment of poisoning by organophosphorus nerve agents. J Toxicol Clin Toxicol 2002; 40: 803-16.

6. Shih TM. Comparison of several oximes on reactivation of soman-induced blood, brain and tissue cholinesterase activity in rats. Arch Toxicol 1993; 67: 637-46.

7. Lorke DE, Kalasz H, Petroianu GA, Tekes K. Entry of oximes into the brain: A review. Curr Med Chem 2008; 15: 743-53.

8. Zdarova Karasova J, Zemek F, Bajgar J et al. Partition of bispyridinium oximes (trimedoxime, K074) administered in therapeutic doses into different parts of the rat brain. J Pharm Biomed Anal 2011; 54: 1082-7.

9. Bajgar J, Fusek J, Kassa J, Kuca K, Jun D. Chemical aspects of pharmacological prophylaxis against nerve agent poisoning. Curr Med Chem 2009; 16: 2977-86.

10. Layish I, Krivoy A, Rotman E, Finkelstein A, Tashma Z, Yehezkelli Y. Pharmacologic prophylaxis against nerve agent poisoning. Isr Med Assoc J 2005; 7: 182-7.

11. Patocka J, Jun D, Bajgar J, Kuca K. Prophylaxis against nerve agent intoxication. Def Sci J 2006; 56: 775-84.

12. Kassa J, Koupilova M., Herink J, Vachek J. The long term influence of low-level sarin exposure on behavioral and neurophysiological functions in rat. Acta Medica (Hradec Kralove) 2001; 44: 21-7.

13. Tallarida R, Murray R. Manual of Pharmacological Calculation with Computer Programs, New York: Springer-Verlag, 1987.

14. Mercey G, Verdelet T, Renou J et al. Reactivators of acetylcholinesterase inhibited by organophosphorus nerve agents. Acc Chem Res 2012; 45: 756-66.

15. Antonijevic B, Stojiljkovic MP. Unequal efficacy of pyridinium oximes in acute organophosphate poisoning. Clin Med Res 2007; 5: 71-82.

16. Marrs TC, Rice P, Vale JA. The role of oximes in the treatment of nerve agent poisoning in civilian casualties. Toxicol Rev 2006; 25: 297-323.

17. Lorke DE, Hasan MY, Nurulain SM, Shafiullah M, Kuca K, Petroianu GA. Acetylcholinesterase inhibitors as pretreatment before acute exposure to organophosphates: assessment using methyl-paraoxon. CNS Neurol Dis Drug Targets 2012; 11: 1052-60.
18. Tuovinen K, Kaliste-Korhonen E, Raushel FM, Hanninen O. Success of pyridostigmine, physostigmine, eptastigmine and phosphotriesterase treatments in acute sarin intoxication. Toxicology 1999; 134: 169-78.

19. Gordon RK, Haigh JR, Garcia GE, Feaster SR, Riel MA, Lenz DE. Oral administration of pyridostigmine bromide and huperzine A protects human whole blood cholinesterases from ex in vivo exposure to soman. Chem-Biol Interact 2005; 157: 239-46.

20. Komloova M, Musilek K, Dolezal M, Gunn-Moore F, Kuca K. Structure-activity relationship of quaternary acetylcholinesterase inhibitors - outlook for early myasthenia gravis treatment. Curr Med Chem 2010; 17: 1810-24.

21. Maxwell DM, Brecht KM, Doctor BP, Wolfe AD. Comparison of antidote protection against soman by pyridostigmine, HI- 6 and acetylcholinesterase. J Pharmacol Exp Therap 1993; 264: 1085-9.

22. Fusek J, Bajgar J, Merka V. Prophylaxe von Vergiftungen mit Nervenkampfstoffen (Ergebnisse einer klinischen Studie). Koord Sanitatsdienst 2006; 24: 48-53.

23. Wenger B, Quigley MD, Kokla MA. Seven-day pyridostigmine administration and thermoregulation during rest and exercise in dry heat. Aviation Space Environ Med 1993; 64: 905-11.

24. Kassa J, Vachek J. A comparison of the efficacy of pyridostigmine alone and the combination of pyridostigmine with anticholinergic drugs as pharmacological pretreatment of tabun-poisoned rats and mice. Toxicology 2002; 177: 179-85.

25. Dunn MA, Hackley BE, Sidell FR. Pretreatment for nerve agent exposure In: Zajtchuk R, Bellamy RF, eds. Textbook of Military Medicine: Medical Aspects of Chemical \& Biological Warfare, Washington DC: Office of the Surgeon General, Department of the Army, 1997: 181-96.

26. Myhrer T, Aas P. Pretreatment and prophylaxis against nerve agent poisoning: Are undesirable behavioral side effects unavoidable? Neurosci Biobehav Rev 2016; 71: 657-70.

27. Abou-Donia MB, Goldstein LB, Jones KH et al. Locomotor and sensorimotor performance deficit in rats following exposure to pyridostigmine bromide, DEET, and permethrin, alone and in combination. Toxicol Sci 2001; 60: 305-14.

28. Kassa J, Musilek K, Koomlova M., Bajgar J. A comparison of the efficacy of newly developed reversible inhibitors of acetylcholinesterase with commonly used pyridostigmine as pharmacological pre-treatment of soman-poisoned mice. Bas Clin Pharmacol Toxicol 2012; 110: 322-6.

29. Lorke DE, Hasan MY, Nurulain SM, Shafiullah M, Kuca K, Petroianu GA. Pretreatment for acute exposure to diisopropylfluorophosphate: in vivo efficacy of various acetylcholinesterase inhibitors. J Appl Toxicol 2011; 31:515-23.

30. Petroianu GA, Hasan MY, Nurulain SM, Arafat K, Sheen R, Nagelkerke N. Comparison of two pre-exposure treatment regimens in acute organophosphate (paraoxon) poisoning in rats: tiapride vs pyridostigmine. Toxicol Appl Pharmacol 2007; 219: 235-40.

31. Petroianu GA, Nurulain SM, Shafiullah M, Hasan MY, Kuca K, Lorke DE. Usefulness of administration of non-organophosphate cholinesterase inhibitors before acute exposure to organophosphates: assessment using paraoxon. J Appl Toxicol 2013; 33: 894-900.

32. Komloova M, Musilek K, Horova A et al. Preparation, in vitro screening and molecular modelling of symmetrical bis-quinolinium cholinesterase inhibitors-implications for early Myasthenia gravis treatment. Bioorg Med Chem Lett 2011; 21: 505-9.

33. Korabecny J, Musilek O, Holas O et al. Synthesis and in vitro evaluation of N-(bromobut-3-en-7-yl)-7-methoxy-1,2,3,4-tetrahydroacridine-9-amine as a cholinesterase inhibitor with regard to Alzheimer's disease treatment. Molecules 2010; 15: 8804-12.

34. Spilovska K, Korabecny J, Kral J et al. 7-methoxy-tacrine-adamantylamine heterodimers as cholinesterase inhibitors in Alzheimer's disease treatment - synthesis, biological evaluation and molecular modeling studies. Molecules 2013; 18: 2397-418.

35. Davis KL, Powchik P. Tacrine. Lancet 1995; 345: 625-30.

36. Gracon SI, Berghoff WG. Cholinesterase inhibition in the treatment of Alzheimer's disease: further evaluation of the clinical effects of tacrine. In Brioni JD, Decker MW, eds. Pharmacological Treatment of Alzheimer's Disease. Molecular and Neurobiological Foundations. New York: Wiley-Liss Inc, 1997: 389-408.

37. Recanatini M, Cavalli A, Belluti F et al. SAR of 9-amino-1,2,3,4-tetrahydroacridine-based acetycholinesterase inhibitors: synthesis, enzyme inhibitory activity, QSAR and structure-based CoMFA of tacrine analogues. J Med Chem 2000; 43: 2007-18.

38. Szymański P, Markowicz M, Mikiciuk-Olasik E. Synthesis and biological activity of derivatives of tetrahydroacridine as acetylcholinesterase inhibitors. Bioorg Chem 2011; 39: 138-42. 
39. Zemek F, Drtinova L, Nepovimova E et al. Outcomes of Alzheimer's disease therapy with acetylcholinesterase inhibitors and memantine. Expert Opin Drug Saf 2014; 13: 759-74.
40. Nepovimova E, Korabecny J, Dolezal R et al. Tacrine-trolox hybrids: a novel class of centrally active, nonhepatotoxic multi-target-directed ligands exerting anticholinesterase and antioxidant activities with low in vivo toxicity. J Med Chem 2015; 58: 8985-9003. 